\title{
A Lotus japonicus Nodulation System Based on Heterologous Expression of the Fucosyl Transferase NodZ and the Acetyl Transferase NolL in Rhizobium leguminosarum
}

\author{
Cristina Pacios Bras, ${ }^{1}$ Meritxell Alberich Jordá, ${ }^{1}$ André H. M. Wijfjes, ${ }^{1}$ Marga Harteveld, ${ }^{1}$ \\ Nico Stuurman, ${ }^{1}$ Jane E. Thomas-Oates, ${ }^{2}$ and Herman P. Spaink ${ }^{1}$ \\ ${ }^{1}$ Leiden University, Institute of Molecular Plant Sciences, Wassenaarseweg 64, 2333 AL Leiden, \\ The Netherlands; ${ }^{2}$ Michael Barber Centre for Mass Spectrometry, UMIST, PO Box 88, Manchester, \\ M60 1QD UK \\ Accepted 17 December 1999.
}

\begin{abstract}
Heterologous expression of NodZ and NolL proteins in Rhizobium leguminosarum bv. viciae led to the production of acetyl fucosylated lipo-chitin oligosaccharides (LCOs), indicating that the NolL protein obtained from Mesorhizobium loti functions as an acetyl transferase. We show that the NolL-dependent acetylation is specific for the fucosyl penta- $N$-acetylglucosamine species. In addition, the NolL protein caused elevated production of LCOs. Efficient nodulation of Lotus japonicus by the NodZ/NolL-producing strain was demonstrated. Nodulation efficiency was further improved by the addition of the ethylene inhibitor L- $\alpha$-(2-aminoethoxyvinyl) glycine (AVG).
\end{abstract}

Additional keywords: acetyl fucose, mass spectrometry, Nod factors.

The induction of root nodules on leguminous plants by rhizobia is mediated by rhizobial Nod factors, which have been identified as lipo-chitin oligosaccharides (LCOs) (Bladergroen and Spaink 1998; van der Drift et al. 1998). Our current studies on the function of Nod factors are being facilitated by the use of the leguminous model plant Lotus japonicus, which is very well suited to genetic analyses (Handberg and Stougaard 1992; Quaedvlieg et al. 1998). For the analysis of the activity of Nod factors it is important to have a well-established bacterial expression system for the genes that are involved in their biosynthesis or secretion. These genes, which are collectively called nod genes, are designated nod, nol, or noe. The function of nod genes can be elegantly demonstrated by a gain of function approach. For example, the activity of the NodZ protein of Bradyrhizobium japonicus as a fucosyl transferase was demonstrated by its expression in Rhizobium leguminosarum bv. viciae and subsequent analysis of the Nod factors produced

Corresponding author: Herman P. Spaink, Leiden University, Institute of Molecular Plant Sciences, Wassenaarseweg 64, 2333 AL Leiden, The Netherlands; Fax: 3171-527 5088; E-mail: Spaink@ rulbim.leidenuniv.nl
(López-Lara et al. 1996). In this paper we use a similar approach to identify the function of the NolL protein of Mesorhizobium loti. An additional goal of these studies was to obtain an efficient heterologous nodulation system for $L$. japonicus, which can also be used for the analysis of factors other than the LCOs involved in infection and nodulation.

In this study, we used $R$. leguminosarum bv. viciae RBL5560 expressing the nodZ gene (on plasmid pMP2450) and the flavonoid independent transcription activation (FITA) nodD gene (on pMP1604) as described previously (LópezLara et al. 1996) (Table 1). Introduction of the nodZ and nodD FITA genes had been shown to result in extension of the host range of RBL5560 to include tropical leguminous plants, such as siratro. Further analysis of the host range of this strain in this study demonstrated that it is also able to nodulate $L$. japonicus (Fig. 1A). However, nodule frequency and number were rather low compared with those induced by the wild-type M. loti strain R7A (Fig. 1A). Since preliminary results indicated that nodulation of $L$. japonicus is strongly inhibited by ethylene (data not shown) we tested the effect of addition of the ethylene production inhibitor L- $\alpha$-(2-aminoethoxyvinyl) glycine (AVG). Results (Fig. 1A) show that nodulation of $L$. japonicus by both strains was greatly stimulated in the presence of $12.7 \mathrm{nM} \mathrm{AVG}$, and that the wild-type strain remained the more efficient nodulator. We assumed that this failure of RBL5560.pMP2450.pMP1604 to exhibit wild-type nodulation was caused by the fact that wild-type LCOs of $M$. loti bear an acetyl moiety on the fucose residue, in addition to methyl and carbamoyl substituents on the nonreducing residue (LópezLara et al. 1995a), which are not present on the LCOs of the $R$. leguminosarum strains (Spaink et al. 1995a). Our attention in this study was directed at examining the effect of the nolL gene on nodulation of L. japonicus. It had previously been shown that nolL functions in the addition of an acetyl group to the fucose residue (Berck et al. 1999; Corvera et al. 1999; Scott et al. 1996). To analyze the function of the nolL gene of $M$. loti in our system it was necessary to reclone the nodZ and nodD FITA genes into one plasmid in order to introduce an 
additional IncP plasmid harboring the nolL gene. Therefore, the nodZ gene from pMP2450 was cloned into pMP1604, resulting in an IncW plasmid (pMP 2469) containing both nodZ and nodD FITA (Table 1). Plasmid pMP2470, an IncP replicon carrying the nolL gene, was introduced into strain RBL5560.pMP2469 and tested for nodulation on L. japonicus. The onset of nodulation (Fig. 1B) for strain RBL5560.pMP2469.pMP2470 was clearly much earlier than for the strain lacking the nolL gene, in both the absence and presence of AVG. The most pronounced effect of the presence of nolL was observed in the absence of AVG, when it resulted in an acceleration of the onset of nodulation from 27 to 13 days.

L. japonicus plants infected with RBL5560.pMP2469 (lacking the nolL gene) grew poorly and leaves became yellow between 25 and 30 days after inoculation, whereas plants infected with the strain expressing nolL (RBL5560.pMP2469.pMP2470) grew as well as plants infected with the wild-type $M$. loti strain R7A and maintained green leaves throughout the duration of the experiment. These observations strongly suggest that nitrogen fixation is taking place in nodules formed in the presence of bacteria expressing nol $L$ and that nitrogen fixation is disturbed in nodules formed by plants inoculated with RBL5560. pMP2469.

The pronounced effects of the inclusion of nolL and nodZ in $R$. leguminosarum bv. viciae on nodulation behavior led us to examine the range and structures of the resulting LCOs, initially with thin-layer chromatography (TLC) and subsequently with high-pressure liquid chromatography (HPLC) isolation of LCOs and structural analysis by nano-electrospray hybrid quadrupole time of flight tandem mass spectrometry (ES-QTof-MS). Small-scale cultures of RBL5560.pMP2469 and RBL5560.pMP2469.pMP2470 were grown in the presence of ${ }^{14} \mathrm{C}$-labeled $\mathrm{N}$-acetyl glucosamine for $18 \mathrm{~h}$ at $28^{\circ} \mathrm{C}$. The cultures were then extracted with $n$-butanol and the radiolabeled LCOs submitted to a preliminary screening with reversedphase TLCs (Fig. 2A; Spaink et al. 1992, 1995a). Surprisingly, the presence of the nolL gene apparently greatly influenced the total amount of radiolabeled LCOs produced (Fig. $2 \mathrm{~A}$, lane 3) as compared with the amounts produced by both the wild-type $R$. leguminosarum bv. viciae (Fig. 2A, lane 1) and the strain containing only the nodZ gene (Fig. 2A, lane 2). The mobility of the major radiolabeled spot resulting from the incorporation of nodZ is increased (Fig. 2A, compare lanes 1 and 2), as expected.

The culture was scaled up to a total of 1 liter, without the use of a radiolabel, and the total LCOs produced were extracted and purified by reversed-phase HPLC as described (López-Lara et al. 1995b; Fig. 2B). Again, it is clear that the total amount of LCOs produced by the strain harboring nolL is much greater than that by the strain lacking nolL. It is very unlikely that this difference reflects an effect on the secretion of the LCOs, since an $n$-butanol extraction method developed for the extraction of total LCOs from whole cells was used (Spaink et al. 1994). The fractions obtained from the strain bearing both nodZ and nolL, corresponding to the material absorbing at $303 \mathrm{~nm}$ and eluting in the $30-40 \%$ acetonitril step gradient, were pooled and submitted to ES-Q-Tof-MS analysis. The mass spectrum (data not shown) contains two major pairs of $\mathrm{M}+\mathrm{K}^{+}$pseudomolecular ions at $\mathrm{m} / z, 1273 / 1279$ and $1518 / 1524$, the latter corresponding to the $\mathrm{C} 18: 4$ and $\mathrm{C} 18: 1$ fatty acyl-bearing $\mathrm{GlcNAc}_{5}$ species having an extra nolLdependent acetyl residue. Very interestingly, the nolLdependent acetyl moiety is not transferred to either the C18:4 or the $\mathrm{C} 18: 1 \mathrm{GlcNAc}_{4}$ analogues, which are thus observed at $m / z$ 1273/1279. There is absolutely no trace of ions corresponding to $\mathrm{GlcNAc}_{4}$ species bearing an extra acetyl group. In addition, there are low abundance ions at $m / z, 1476 / 1482$ for C18:4 and C18:1 GlcNAc 5 species without the nolL-dependent acetyl group. Tandem MS analysis of the ion at $\mathrm{m} / \mathrm{z} 1518$ for the C18:4 fatty acyl-bearing species (data not shown) yielded B ions at $m / z 703\left(\mathbf{B}_{2}\right), 906\left(\mathbf{B}_{3}\right)$, and $1109\left(\mathbf{B}_{4}\right), \mathbf{Y}$ ions at $m / z$ $651\left(\mathrm{Y}_{2}\right), 854\left(\mathrm{Y}_{3}\right)$, and $1057\left(\mathrm{Y}_{4}\right)$, and, importantly, a $\beta$ cleavage ion at $\mathrm{m} / \mathrm{z}, 1330$ arising by loss of an acetylated fucosyl residue, together demonstrating that the additional acetyl moiety is located on the nodZ-dependent fucosyl residue. Tandem MS analysis of the ion at $\mathrm{m} / z, 1524$ (Fig. 3) corresponding to the $\mathrm{C} 18$ :1-bearing species generated ions at $\mathrm{m} / \mathrm{z} 709\left(\mathrm{~B}_{2}\right)$, $912\left(\mathrm{~B}_{3}\right)$, and $1115\left(\mathrm{~B}_{4}\right), 651\left(\mathrm{Y}_{2}\right), 854\left(\mathrm{Y}_{3}\right)$, and $1057\left(\mathrm{Y}_{4}\right)$, and a $\beta$-cleavage ion for the loss of an acetyl fucose at $\mathrm{m} / \mathrm{z}$ 1336. A similar mass spectrometric analysis of the LCOs from the control strain in which the nolL gene was not present showed the complete absence of LCOs containing an acetylfucose, confirming earlier results of López-Lara et al. (1996).

The structure determination results demonstrate clearly that the noll gene is involved in the transfer of an acetyl to the

Table 1. Strains and plasmids ${ }^{\mathrm{a}}$

\begin{tabular}{|c|c|c|}
\hline Strains & Description & Source/reference \\
\hline RBL5560 & $\begin{array}{l}\text { LPR5045 (Rhizobium leguminosarum bv. trifolii cured from its own Sym plasmid) provided with Sym } \\
\text { plasmid pJB5JI (= pRL1JI mep::Tn 5) derived from } R \text {. leguminosarum bv. viciae, } \text { Rif }^{r}\end{array}$ & Spaink et al. 1987 \\
\hline R7A & Wild-type Mesorhizobium loti, Rif $^{\mathrm{T}}$ derived from NZP2238 & Sullivan et al. 1995 \\
\hline \multicolumn{3}{|c|}{ 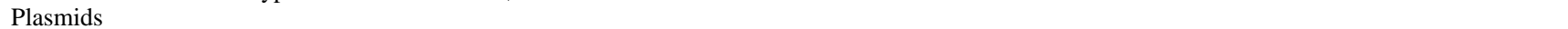 } \\
\hline pMP604 & IncP, $\mathrm{Tc}^{\mathrm{r}}$, contains nodD FITA & Spaink et al. 1989 \\
\hline pRI40 & IncW, $\mathrm{sp}^{\mathrm{r}}$ & Innes et al. 1988 \\
\hline pMP1604 & IncW, $\mathrm{sp}^{\mathrm{r}}$, contains nodD FITA from pMP604 inserted into pRI40 & López-Lara et al. 1996 \\
\hline pMP1060 & IncP, $\mathrm{Tc}^{\mathrm{r}}$, contains nodD from $R$. leguminosarum bv. viciae & Bloemberg et al. 1994 \\
\hline pMP3510 & IncP, $\mathrm{Tc}^{\mathrm{r}}$, contains a polylinker & Spaink et al. 1995b \\
\hline pMP2450 & IncP, $\mathrm{Tc}^{\mathrm{r}}$, contains nodZ of $B$. japonicum & López-Lara et al. 1996 \\
\hline pPN383 & Contains nolL from NZP2037 & Scott et al. 1996 \\
\hline pMP2469 & $\begin{array}{l}\text { IncW, Sp }{ }^{\mathrm{r}}, \mathrm{Sm}^{\mathrm{r}} \text {, contains } n o d Z \text { and FITA nodD. nodZ was transferred as a PstI fragment from pMP2450 } \\
\text { into pMP1604 }\end{array}$ & This work \\
\hline pMP2470 & IncP, Tc ${ }^{r}$; contains NolL from pPN383 inserted into pMP3510 as a 2.4-kb BamHI fragment & This work \\
\hline
\end{tabular}

${ }^{\mathrm{a}} \mathrm{Km}^{\mathrm{r}}, \mathrm{Sp}^{\mathrm{r}}, \mathrm{Tc}^{\mathrm{r}}$, and Rif': kanamycin, spectinomycin, tetracycline, and rifampicin resistance; Inc: plasmid incompatibility group; FITA: flavonoid independent transcription activation. 
fucose residue. These results are consistent with those obtained previously (Corvera et al. 1999; Berck et al. 1999) for the nolL genes of $R$. etli and Rhizobium sp. strain NGR234, respectively. Considering the homology of the predicted NolL protein sequence with that of other proteins assumed to be acetyltransferases (Scott et al. 1996), this function for NolL is not surprising. What is remarkable, however, is that the substrate specificity of the NolL protein appears to be restricted in the same way as that of the NodX protein, both transferring an acetyl group only to the GlcNAc ${ }_{5}$ species (Firmin et al. 1993). Since the two predicted protein sequences have only $25 \%$ amino acid identity, this striking conservation of acceptor specificity could not have been predicted. Even more unexpected is the observation that the NolL protein greatly increases the quantity of LCOs produced. The introduction of such a new activity might have been expected to decrease rather than to increase the activity of the other biosynthetic enzymes involved in LCO production. Currently, we have no obvious explanation for this phenomenon. The acetyl transferase NodL has also been shown to increase the production of Nod factors (Spaink et al. 1992), the molecular basis for which is also not understood. The increased LCO production is very convenient for obtaining large quantities of suitably modified LCOs for both biological and structural studies. However, it makes it difficult to conclude whether the improved nodulation characteristics conferred by nolL are due to its transacetylation activity or purely to the larger quantities of LCOs produced.

In addition to the advantages of a heterologous expression system for demonstrating the biochemical function of a pro-

\section{A}

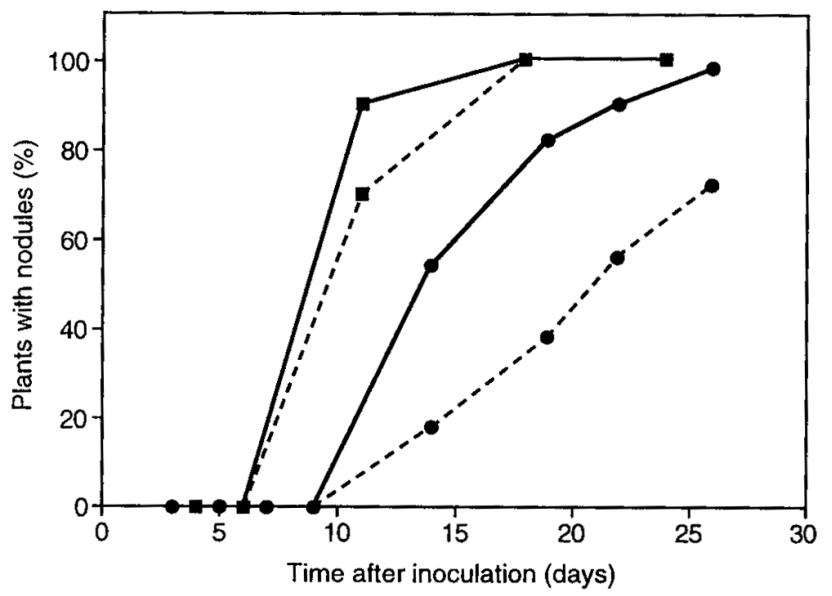

C

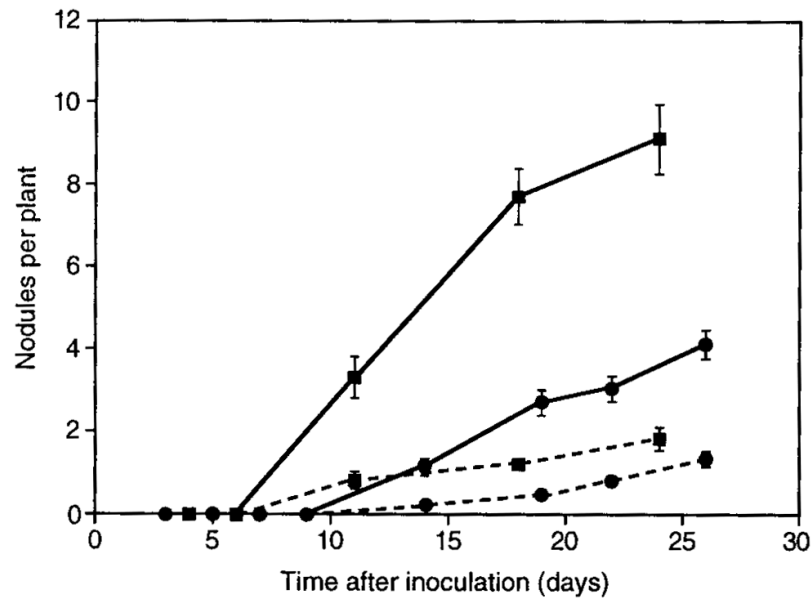

B

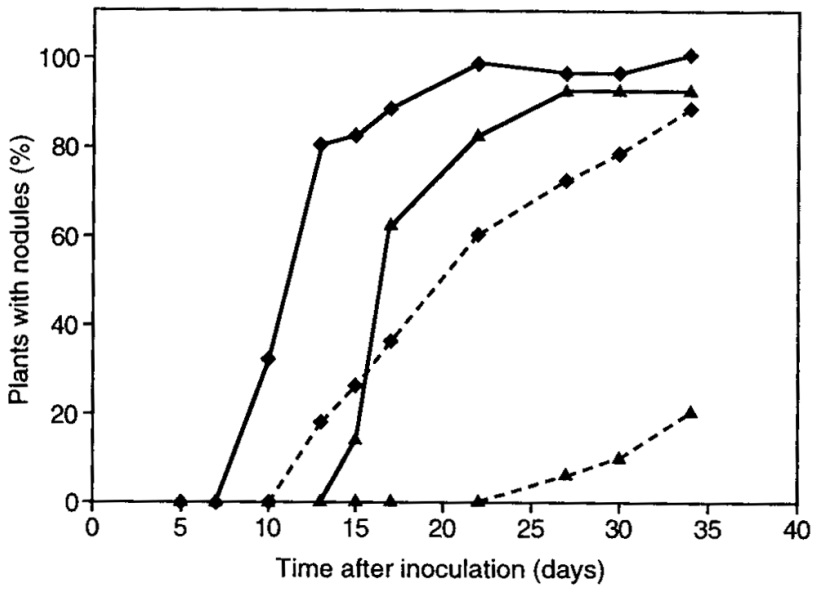

D

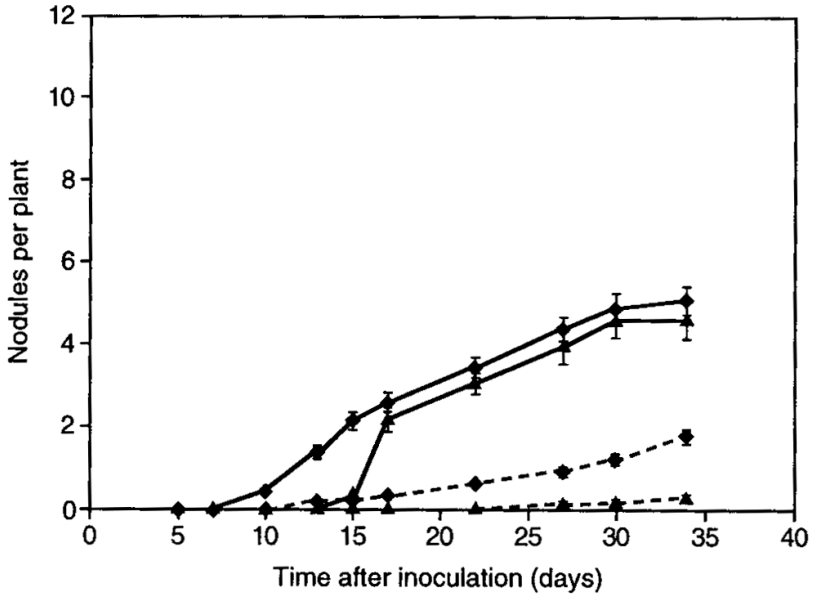

Fig. 1. Effects of expression of the nodZ and nolL genes on nodulation of Lotus japonicus plants infected with Rhizobium leguminosarum bv. viciae. A and $\mathbf{B}$, Percentage of plants with nodules. $\mathbf{C}$ and $\mathbf{D}$, Average number of nodules per nodulated plant, with the strains listed below for the two sets of experiments (A-C and B-D). Nodulation characteristics were compared with those of the wild-type Mesorhizobium loti strain R7A. Seeds were surface sterilized with $1 \mathrm{M} \mathrm{H}_{2} \mathrm{SO}_{4}$ for $2 \mathrm{~min}$ and, after being washed with water, incubated in bleach for $10 \mathrm{~min}$, and washed again with water overnight, vernalized for 2 days at $4^{\circ} \mathrm{C}$ on agar plates. Germination was performed overnight at $28^{\circ} \mathrm{C}$. Plants were grown in petri dishes containing Jensen medium solidified with $1.2 \%$ Daishin agar in which the roots were shielded from light. Incubation was at $20^{\circ} \mathrm{C}$ in a growth room with an $8 \mathrm{~h} \mathrm{dark}, 16 \mathrm{~h} \mathrm{light}$ cycle. When added to the plates, the ethylene inhibitor L- $\alpha$-(2-aminoethoxyvinyl) glycine (AVG) concentration was $12.7 \mathrm{nM}$. Results shown are for one representative experiment out of three performed with 50 plants for each inoculation with RBL5560. M. loti R7A inoculations were performed with 10 plants.

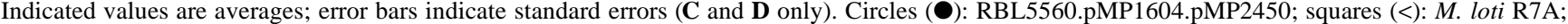
diamonds $(\diamond)$ : RBL5560.pMP2469.pMP2470; triangles $(\boldsymbol{\Delta})$ : RBL5560.pMP2469. Continuous and dashed lines represent presence and absence of AVG, respectively. 
tein, as demonstrated here, there are also several obvious advantages for biological studies. These include the absence of a genetic background that could include genes having the same biological function as the gene under study. A good example is that of the nod $O$ gene of $R$. leguminosarum bv. viciae, encoding a secreted protein that is able to complement defects in genes responsible for modifications of the endogenous LCOs
(Downie and Surin 1990). Our test system can be used to analyze the effect on nodulation of L. japonicus of wellcharacterized mutations in $R$. leguminosarum genes, such as, for instance, those involved in exopolysaccharide (EPS) biosynthesis or avirulence (Pollock et al. 1998; Roest et al. 1997). The availability of an efficient, heterologous nodulation system for L. japonicus will enable our further studies of bacterial
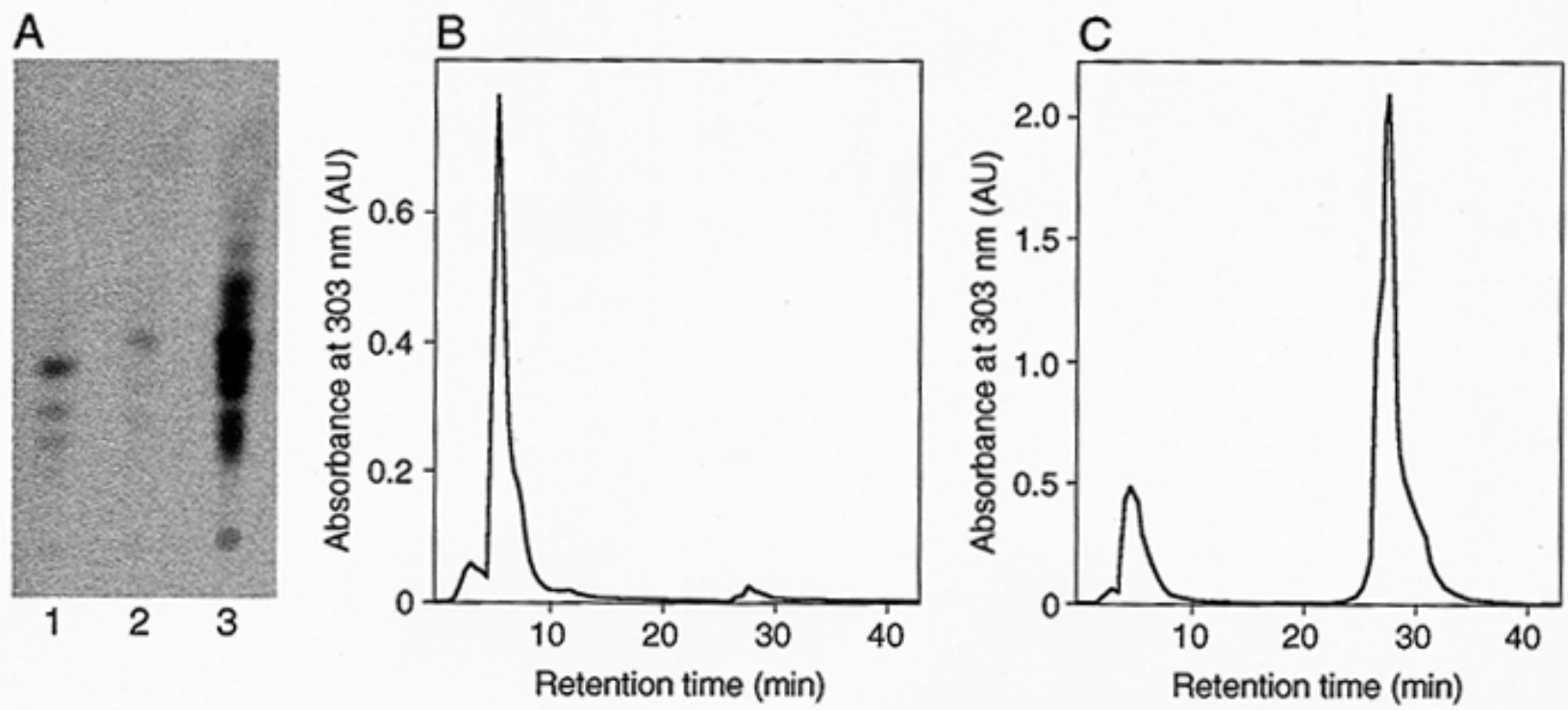

Fig. 2. Purification of lipo-chitin oligosaccharides (LCOs). A, Thin-layer chromatography (TLC) analysis of LCOs. Lane 1: RBL5560. Lane 2: RBL5560.pMP2469. Lane 3: RBL5560.pMP2469.pMP2470. B and C, High-pressure liquid chromatography (HPLC) profiles of $n$-butanol extracts from (B) RBL5560.pMP2469 and (C) RBL5560.pMP2469.pMP2470 cultures. Amount of sample loaded was equivalent to that isolated from $100 \mathrm{ml}$ of culture. Purification protocol is described in López-Lara et al. (1995a). Isocratic elution with 30\% acetonitrile (20 min) was followed by $30 \mathrm{~min}$ of isocratic elution with $40 \%$ acetonitrile. HPLC elution was performed at a flow rate of $1 \mathrm{ml} / \mathrm{min}$. There are differences in scale between the two chromatograms.
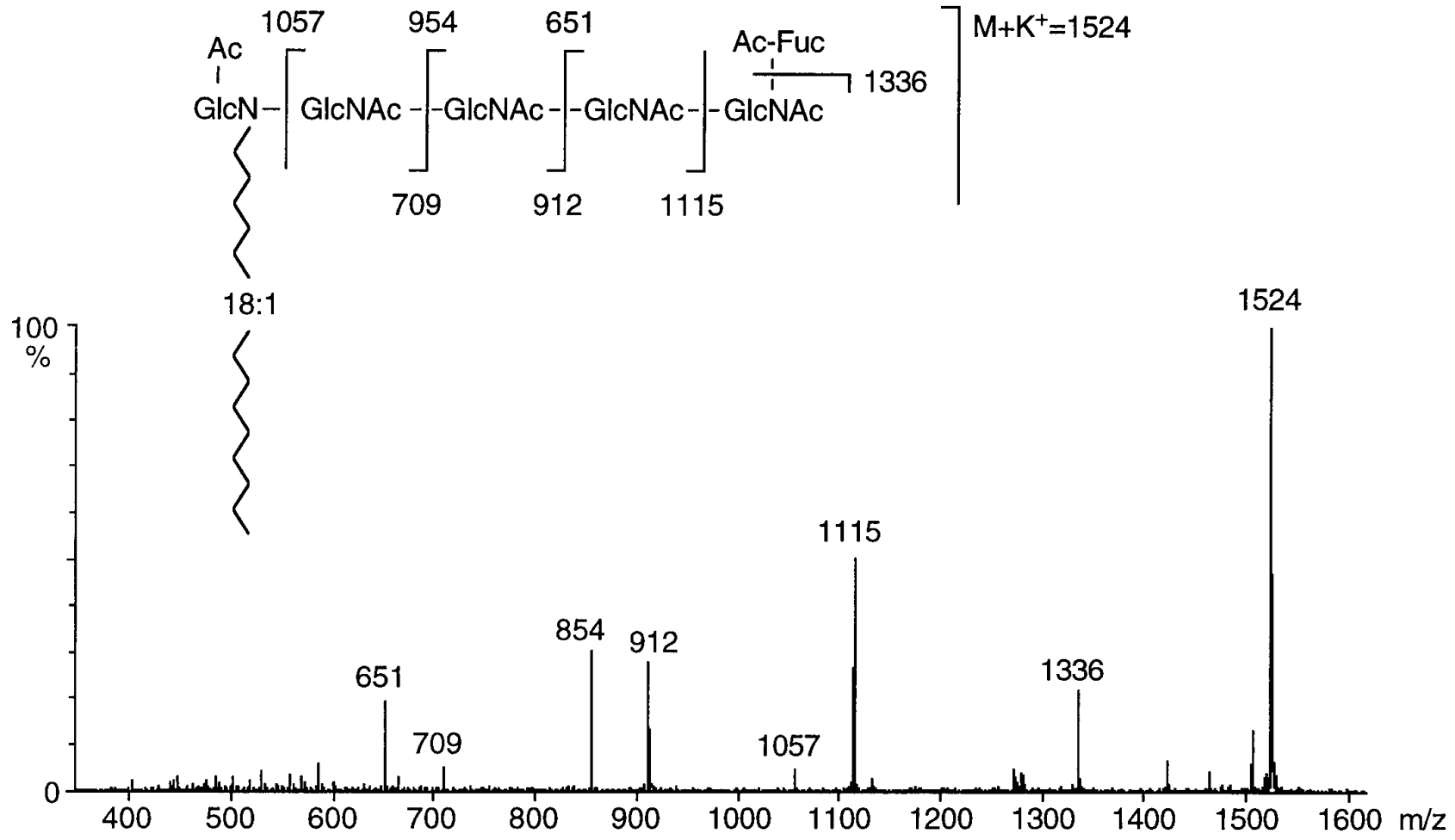

Fig. 3. Tandem mass spectrum and fragmentation diagram obtained from the $\mathrm{M}+\mathrm{K}^{+}$pseudomolecular ion for $\mathrm{V}(18: 4, \mathrm{AcFuc})$ at $m / z$. 1524 . 
host-specific genes required for efficient infection and nitrogen fixation in L. japonicus with a similar gain of function approach.

\section{ACKNOWLEDGMENTS}

It is a pleasure to thank Peter Hock for his skillful assistance in preparing the figures. J. T.-O. gratefully acknowledges financial support (to S. J. Gaskell and R. J. Beynon) from the Higher Education Funding Council for England, with additional support from Smith Kline Beecham, UMIST, University of Wales College of Medicine and Chugai Pharmaceuticals, for the purchase of the Q-Tof.

\section{LITERATURE CITED}

Berck, S., Perret, X., Quesada, V. D., Promé, J.-C., Broughton, W. J., and Jabbouri, S. 1999. NolL of Rhizobium sp. strain NGR234 is required for $O$-acetyltransferase activity. J. Bacteriol. 181:957-964.

Bladergroen, M., and Spaink, H. P. 1998. Genes and signal molecules involved in the rhizobia-leguminoseae symbiosis. Curr. Opin. Plant Biol. 1:353-359.

Bloemberg, G. V., Thomas-Oates, J. E., Lugtenberg, B. J. J., and Spaink, H. P. 1994. Nodulation protein NodL of Rhizobium leguminosarum Oacetylates lipo-oligosaccharides, chitin fragments and $\mathrm{N}$-acetylglucosamine in vitro. Mol. Microbiol. 11:793-804.

Corvera, A., Promé, D., Promé, J.-C., Martínez-Romero, E., and Romero, D. 1999. The nolL gene from Rhizobium etli determines nodulation efficiency by mediating the acetylation of the fucosyl residue in the nodulation factor. Mol. Plant-Microbe Interact. 12:236-246.

Downie, J. A., and Surin, B. P. 1990. Either of two nod gene loci can complement the nodulation defect of a nod deletion mutant of Rhizobium leguminosarum bv. viciae. Mol. Gen. Genet. 222:81-86.

Firmin, J. L., Wilson, K. E., Carlson, R. W., Davies, A. E., and Downie, J. A. 1993. Resistance to nodulation of cv. Afghanistan peas is overcome by nodX which mediates an O-acetylation of the Rhizobium leguminosarum lipo-oligosaccharide nodulation factor. Mol. Microbiol. 10:351-360.

Handberg, K., and Stougaard, J. 1992. Lotus japonicus, an autogamus, diploid legume species for classical and molecular genetics. Plant J. 2: 487-496.

Innes, R. W., Hirose, M. A., and Kuempel, P. L. 1988. Induction of nitrogen-fixing nodules on clover requires only 32 kilobase pairs of DNA from the Rhizobium trifolii symbiosis plasmid. J. Bacteriol. 170: 3793-3802.

López-Lara, I. M., Blok-Tip, L., Quinto, C., Garcia, M. L., Stacey, G., Bloemberg, G. V., Lamers, G. E. M., Lugtenberg, B. J. J., ThomasOates, J. E., and Spaink, H. P. 1996. NodZ of Bradyrhizobium extends the nodulation host range of Rhizobium by adding a fucosyl residue to nodulation signals. Mol. Microbiol. 21:397-408.

López-Lara, I. M., van den Berg, J. D. J., Thomas-Oates, J. E., Glushka, J., Lugtenberg, B. J. J., and Spaink, H. P. 1995a. Structural identification of the lipo-chitin oligosaccharide nodulation signals of Rhizobium loti. Mol. Microbiol. 15:627-638.
López-Lara, I. M., van der Drift, K. M. G. M., van Brussel, A. A. N., Haverkamp, J., Lugtenberg, B. J. J., Thomas-Oates, J. E., and Spaink, H. P. 1995b. Induction of nodule primordia on Phaseolus and Acacia by lipo-chitin oligosaccharide nodulation signals from broad host range Rhizobium strain GRH2. Plant Mol. Biol. 29:465-477.

Pollock, T. J., van-Workum, W. A., Thorne, L., Mikolajczak, M. J., Yamazaki, M., Kijne, J. W., and Armentrout, R. W. 1998. Assignment of biochemical functions to glycosyl transferase genes which are essential for biosynthesis of exopolysaccharides in Sphingomonas strain S88 and Rhizobium leguminosarum. J. Bacteriol. 180:586-593.

Quaedvlieg, N. E. M., Schlaman, H. R. M., Admiraal, P. C., Wijting, S. E., Stougaard, J., and Spaink, H. P. 1998. Fusions between green fluorescent protein and $\beta$-glucuronidase as sensitive and vital bifunctional reporters in plants. Plant Mol. Biol. 37:715-727.

Roest, H. P., Mulders, I. H., Spaink, H. P., Wijffelman, C. A., and Lugtenberg, B. J. J. 1997. A Rhizobium leguminosarum biovar trifolii locus not localized on the sym plasmid hinders effective nodulation on plants of the pea cross-inoculation group. Mol. Plant-Microbe. Interact. 10:938-941.

Scott, D. B., Young, C. A., Collins-Emerson, J. M., Terzaghi, E. A., Rockman, E. S., Lewis, P. E., and Pankhurst, C. E. 1996. Novel and complex chromosomal arrangement of Rhizobium loti nodulation genes. Mol. Plant-Microbe Interact. 9:187-197.

Spaink, H. P., Aarts, A., Stacey, G., Bloemberg, G. V., Lugtenberg, B. J. J., and Kennedy, E. P. 1992. Detection and separation of Rhizobium and Bradyrhizobium Nod metabolites using thin layer chromatography. Mol. Plant-Microbe Interact. 5:72-80.

Spaink, H. P., Bloemberg, G. V., van Brussel, A. A. N., Lugtenberg, B. J. J., van der Drift, K. M. G. M., Haverkamp, J., and Thomas-Oates, J. E. 1995a. Host specificity of Rhizobium leguminosarum is determined by the hydrophobicity of highly unsaturated fatty acyl moieties of the nodulation factors. Mol. Plant-Microbe Interact. 8:155-164.

Spaink, H. P., Okker, R. J. H., Wijffelman, C. A., Pees, E., and Lugtenberg, B. J. J. 1987. Promoters in the nodulation region of the Rhizobium leguminosarum Sym plasmid pRL1JI. Plant Mol. Biol. 9:27-39.

Spaink, H. P., Okker, R. J. H., Wijffelman, C. A., Tak, T., GoosendeRoo, L., Pees, E., van Brussel, A. A. N., and Lugtenberg, B. J. J. 1989. Symbiotic properties of rhizobia containing a flavonoid-independent hybrid nodD product. J. Bacteriol. 171:4045-4053.

Spaink, H. P., Wijfjes, A. H. M., and Lugtenberg, B. J. J. 1995b. Rhizobium NodI and NodJ proteins play a role in the efficiency of secretion of lipochitin oligosaccharides. J. Bacteriol. 177:6276-6281.

Spaink, H. P., Wijfjes, A. H. M., van der Drift, K. M. G. M., Haverkamp, J., Thomas-Oates, J. E., and Lugtenberg, B. J. J. 1994. Structural identification of metabolites produced by the NodB and NodC proteins of Rhizobium leguminosarum. Mol. Microbiol. 13:821-831.

Sullivan, J. T., Patrick, H. N., Lowther, W. L., Scott, D. B., and Ronson, C. W. 1995. Nodulating strains of Rhizobium loti arise through chromosomal symbiotic gene transfer in the environment. Proc. Natl. Acad. Sci. USA 92:8985-8989.

van der Drift, K. M. G. M., Olsthoorn, M. M. A., Brull, L. P., Blok, T. L., and Thomas-Oates, J. E. 1998. Mass spectrometric analysis of lipo-chitin oligosaccharides - signal molecules mediating the hostspecific legume-rhizobium symbiosis. Mass Spectrom. Rev. 17:75-95. 